\title{
Study on Life Cycle Management System for Main condensers in Nuclear Power Plant
}

\author{
Yang Jie ${ }^{1}$, Yuan Liang ${ }^{1}$, Yang $\mathrm{Wu}^{1}$, Qin Qiang ${ }^{1}$ \\ ${ }^{1}$ Suzhou Nuclear Power Research Institute, No.1688, Xihuan Road, Suzhou City, Jiangsu Province, China
}

\begin{abstract}
Daya Bay Nuclear Power Plant has been running for above 20 years. main condensers have begun to run during the commissioning phase before the official commercial operation, so it is imminent to carry out the life cycle management of main condensers combined with demonstration of the operation license extended to 60 years. A life cycle management system for main condensers in nuclear power plant is established in this paper, which is applied to management practices of Daya Bay Nuclear Power Plant.
\end{abstract}

\section{Introduction}

Daya Bay Nuclear Power Plant has been running for more than 20 years ${ }^{[1]}$.It is imminent to carry out the management of the life period of major equipment, considering the actual operation state of chillers and research work of nuclear operation license extension to 60 years. Life cycle management is a process of managing equipment in nuclear power plant actively to make power plant achieve the optimal overall performance (security, reliability, and economy), which will maximize the value of the enterprise.

Main condensers in nuclear power plant are important equipment of the secondary loop thermal system, and at present, main condensers of domestic nuclear power plant are mostly surface heat exchangers. After working in the low-pressure steam turbine, the exhaust steam enters the main condensers and flows through the outer side of the titanium tube, while the circulating seawater flows through the inner side of the titanium tube. The exhaust steam condenses into water on the outer surface of the heat transferring tube, and the vaporization latent heat is released and taken away by the circulating seawater.

Some countries like USA, Canada, Korea, Japan and France have already formed relatively complete equipment life cycle management system for main condensers, which have been effectively applied. Among them, nuclear power plants in United States are the first to carry out the life cycle management work for main condensers taking the advantages of research of EPRI (Electric Power Research Institute), INPO (Institute of Nuclear Power Operations) and NEI (Nuclear Energy Institute) and other institutions ${ }^{[2]-[4]}$. Domestic nuclear power plants have not systematically carried out the analysis and research on the life cycle management of major equipment before 2010, and the life cycle management for main condensers has not yet formed a complete system.

In this paper, main condensers that are important equipment of the second loop in Daya Bay nuclear power plant, which has been in service for the longest time in China, is taken as the research object. And its life cycle management boundary scope determination, concerned parts screening, equipment problem collection and screening, concerned technical analysis, concerned problem risk analysis, equipment component life assessment, formulation of life cycle management strategies are studied. This management system has been successfully applied in Daya Bay nuclear power plant.

\section{Life cycle management system for main condensers in nuclear power plant}

The life cycle management evaluation of main condensers in Daya Bay nuclear power plant was carried out based on the life cycle management system in nuclear power plant established in this paper, which is shown as Figure 1, and it includes life cycle management boundary determination, concerned components screening, collection and screening equipment concerned problems, technical analysis of concerned problems, risk analysis of concerned problems, components and equipment life evaluation, formulation of life cycle management options, comparison and analysis of alternatives, making the optimal life cycle management.

\footnotetext{
* Corresponding author: yjie@ecgnpc.com.cn
} 


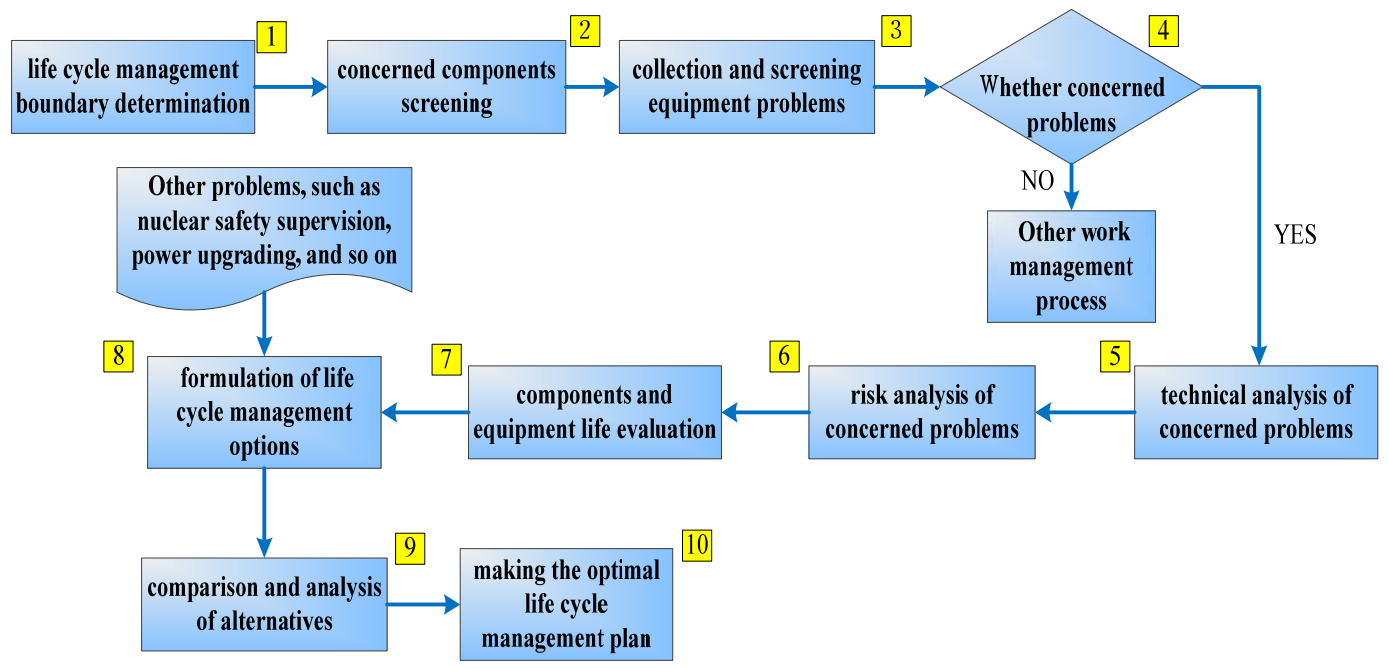

Figure 1. The life cycle management process of main condensers in nuclear power plant

\section{Life cycle management evaluation of main condensers in nuclear power plant}

\subsection{Life cycle management boundary determination}

The boundary of the life cycle management defines the research object and the scope of the life cycle management for main condensers in nuclear power plant. Main condensers in Daya Bay nuclear plant refer to the equipment bodies and their sub components, and the interface with other systems is bounded by the first isolation valves. The life cycle management boundary for main condensers includes the mechanical boundary and the controlling boundary. There are 42 component parts within the above mentioned boundary.

\subsection{Concerned components screening}

Concerned components screening of life cycle management for main condensers is based on the key function of main condensers. All the important parts within the boundary range of main condensers are classified according to failure consequence and failure probability, which is shown in Table 1. Components ranking level 1-6 in Table 1 are selected as concerned components of life cycle management for main condensers.

According to the principle of concerned components screening, the concerned components of main condensers in Daya Bay nuclear power plant comprises 7 parts, which includes balance expansion joints, dog-bone expansion joints, tube plates, titanium tubes, inlet waterboxes, outlet waterboxes, tube plugs.
Table 1. Component screening grading table

\begin{tabular}{|c|c|c|c|c|c|c|c|c|c|c|}
\hline \multicolumn{2}{|c|}{ Component grade } & 1 & 2 & 3 & 4 & 5 & 6 & 7 & 8 & 9 \\
\hline \multirow{3}{*}{ Failure consequence } & High & $\mathrm{x}$ & $\mathrm{x}$ & $\mathrm{x}$ & & & & & & \\
\hline & Medium & & & & $\mathrm{x}$ & $\mathrm{x}$ & & $\mathrm{x}$ & & \\
\hline & Low & & & & & & $\mathrm{X}$ & & $\mathrm{x}$ & $\mathrm{x}$ \\
\hline \multirow{3}{*}{ Failure probability } & High & $\mathrm{x}$ & & & $\mathrm{x}$ & & $\mathrm{X}$ & & & \\
\hline & Medium & & $\mathrm{x}$ & & & $\mathrm{x}$ & & & $\mathrm{x}$ & \\
\hline & Low & & & $\mathrm{x}$ & & & & $\mathrm{x}$ & & $\mathrm{x}$ \\
\hline
\end{tabular}

\subsection{Collection and screening equipment concerned problems}

The collection of life cycle problems is to set up a list of life cycle problems for main condensers in nuclear power plant. The life cycle issues include power plant internal operation experiences and performance data, operation problems and elimination problems. After establishing the list of life cycle problems, screening these problems according to the impact degree and resources needed to carry out the solutions. Problems meeting to one of the following criteria are selected as life cycle management concerned problems.

Screening criteria is illustrated as below:

1) Known equipment problems that the existing preventive maintenance cannot effectively solve or whose consequences are unacceptable;

2) Problems that solving may extend outage duration

3) Problems that solving is expected to require capital investment of more than 800 thousand RMB.

After screening based on the above-mentioned criteria, concerned problems of main condensers in Daya Bay nuclear power plant are shown as Table 2.

Table 2. concerned problems of main condensers

\begin{tabular}{|c|c|l|c|c|c|}
\hline No. & Item No. & Concerned component & Problem description & Problem type & $\begin{array}{c}\text { Whether } \\
\text { concerned } \\
\text { problem }\end{array}$ \\
\hline 1 & CEX-4 & $\begin{array}{l}\text { Balance expansion joints } \\
\text { between main condensers }\end{array}$ & Aging of bellow & Potential problem & YES \\
\hline 2 & CEX-5 & Dog bone expansion joints & $\begin{array}{c}\text { Aging and damage of dog-bone } \\
\text { expansion joints }\end{array}$ & Potential problem & YES \\
\hline 3 & CEX-7 & Tubeplates & Leakage of Tubeplates & Potential problem & YES \\
\hline
\end{tabular}




\begin{tabular}{|c|c|c|c|c|c|}
\hline 4 & \multirow{3}{*}{ CEX-8 } & \multirow{3}{*}{ Titanium tube } & $\begin{array}{l}\text { Coolling seawater leakage of } \\
\text { titanium tube thinning and } \\
\text { perforation caused by scouring } \\
\text { of steam and drainage }\end{array}$ & Potential problem & YES \\
\hline 5 & & & \begin{tabular}{|c|} 
Coolling seawater leakage of \\
titanium tube caused by rubbing \\
and fracture
\end{tabular} & Potential problem & YES \\
\hline 6 & & & \begin{tabular}{|c|} 
High plugging rate of titanium \\
tube
\end{tabular} & Potential problem & YES \\
\hline 7 & \multirow{3}{*}{$\begin{array}{l}\text { CEX-10 } \\
\text { CEX-11 }\end{array}$} & \multirow{3}{*}{$\begin{array}{l}\text { Inlet waterboxes } \\
\text { Outlet waterboxes }\end{array}$} & $\begin{array}{c}\text { Corrosion at the joint of } \\
\text { waterboxes and tubeplates }\end{array}$ & Existing problem & YES \\
\hline 8 & & & $\begin{array}{c}\text { Corrosion of waterbox } \\
\text { components caused by } \\
\text { waterbox rubber aging and } \\
\text { even local rubber falling off }\end{array}$ & Existing problem & YES \\
\hline 9 & & & Aging of waterbox flange seal & Potential problem & YES \\
\hline 10 & CEX-38 & Tube plug & Falling off failure of tube plugs & Potential problem & YES \\
\hline
\end{tabular}

\subsection{Technical analysis and risk assessment of concerned problems}

Identify the current status of the equipment, including the existing problems and potential risks, clarify the existing problems and potential risks, and screen the mature processing methods in the industry, so as to prepare for the formulation of life cycle management plans. The following aspects can be referred in the technical evaluation: Identify the current equipment problems, and make judgments based on the importance, severity and urgency of the consequences; a preliminary analysis of the causes of the current problems, utilization of horizontal research results.

For the concerned problems of life cycle management, evaluate the failure consequence and failure probability of equipment components involved in problems, and determine the problem risk level referring to the risk assessment method. The results of the concerned problems risk level are as shown in table 3 .

Table 3. Results of risk assessment for concerned problems of main condensers

\begin{tabular}{|c|c|c|c|c|c|c|}
\hline \multirow{3}{*}{ Item No. } & \multirow[b]{3}{*}{ Component } & \multirow[b]{3}{*}{ Concerned problems } & \multirow{3}{*}{$\begin{array}{l}\text { failure consequence } \\
\text { (high/medium/low) }\end{array}$} & \multirow{2}{*}{\multicolumn{2}{|c|}{ failure probability }} & \\
\hline & & & & & & \multirow{2}{*}{$\begin{array}{c}\text { Problem risk } \\
\text { level }\end{array}$} \\
\hline & & & & Evaluation time limit & $\begin{array}{l}\text { Evaluation } \\
\text { results }\end{array}$ & \\
\hline \multirow{3}{*}{ CEX-4 } & \multirow{3}{*}{$\begin{array}{l}\text { Balance expansion } \\
\text { joints between main } \\
\text { condensers }\end{array}$} & \multirow{3}{*}{ Aging of bellow } & \multirow{3}{*}{ High } & Year 0-5 & Low & Medium \\
\hline & & & & Year 6-10 & Low & Medium \\
\hline & & & & Year 11 to the end of life & Low & Medium \\
\hline \multirow{3}{*}{ CEX-5 } & \multirow{3}{*}{$\begin{array}{l}\text { Dog-bone expansion } \\
\text { joints }\end{array}$} & \multirow{3}{*}{$\begin{array}{llr}\text { Aging } & \text { and } & \text { damage } \\
\text { of } & \text { dog } & \text { bone } \\
\text { expansion joints }\end{array}$} & \multirow{3}{*}{ High } & Year 0-5 & Low & Medium \\
\hline & & & & Year 6-10 & Low & Medium \\
\hline & & & & Year 11 to the end of life & Low & Medium \\
\hline \multirow{3}{*}{ CEX-7 } & \multirow{3}{*}{ Tubeplates } & \multirow{3}{*}{$\begin{array}{l}\text { Leakage } \\
\text { Tubeplates }\end{array}$} & \multirow{3}{*}{ High } & Year $0-5$ & Low & Medium \\
\hline & & & & Year 6-10 & Low & Medium \\
\hline & & & & Year 11 to the end of life & Low & Medium \\
\hline \multirow{9}{*}{ CEX-8 } & \multirow{9}{*}{ Titanium tube } & \multirow{3}{*}{$\begin{array}{l}\text { Cooling sea water } \\
\text { leakage of titanium } \\
\text { tube thinning and } \\
\text { perforation caused } \\
\text { by scouring of } \\
\text { steam and drainage }\end{array}$} & \multirow{3}{*}{ High } & Year $0-5$ & Low & Medium \\
\hline & & & & Year 6-10 & Low & Medium \\
\hline & & & & Year 11 to the end of life & Low & Medium \\
\hline & & \multirow{3}{*}{$\begin{array}{l}\text { Cooling sea water } \\
\text { leakage of titanium } \\
\text { tube caused by } \\
\text { rubbing and fracture }\end{array}$} & \multirow{3}{*}{ High } & Year 0-5 & Low & Medium \\
\hline & & & & Year 6-10 & Low & Medium \\
\hline & & & & Year 11 to the end of life & Low & Medium \\
\hline & & \multirow{3}{*}{ High plugging rate } & \multirow{3}{*}{ High } & Year 0-5 & Low & Medium \\
\hline & & & & Year 6-10 & Low & Medium \\
\hline & & & & Year 11 to the end of life & Low & Medium \\
\hline \multirow{6}{*}{\begin{tabular}{|l} 
CEX-10 \\
CEX-11
\end{tabular}} & \multirow{6}{*}{$\begin{array}{l}\text { Inlet waterboxes } \\
\text { Outlet waterboxes }\end{array}$} & \multirow{3}{*}{$\begin{array}{l}\text { Corrosion at the joint } \\
\text { of waterboxes and } \\
\text { tube plate }\end{array}$} & \multirow{3}{*}{ Low } & Year $0-5$ & Low & Low \\
\hline & & & & Year 6-10 & Medium & Low \\
\hline & & & & Year 11 to the end of life & Medium & Low \\
\hline & & \multirow{3}{*}{\begin{tabular}{|l|} 
Corrosion of \\
waterbox \\
components caused \\
by waterbox rubber \\
\end{tabular}} & \multirow{3}{*}{ High } & Year $0-5$ & Medium & High \\
\hline & & & & Year 6-10 & Low & Low \\
\hline & & & & Year 11 to the end of life & Medium & High \\
\hline
\end{tabular}




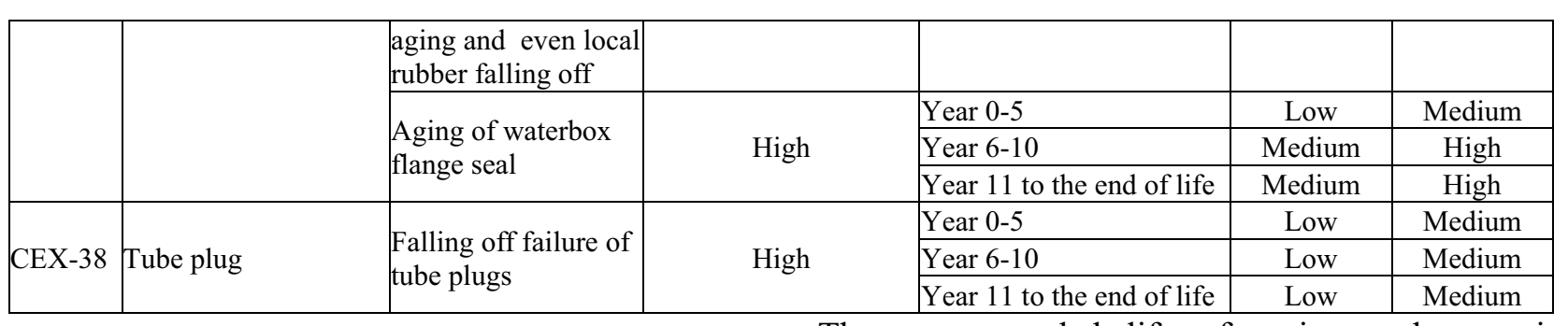

\section{5 components and equipment life evaluation}

Component and equipment life evaluation includes failure mode analysis, aging state management, aging life assessment, experience feedback life assessment, and reliability life assessment.

\subsubsection{Failure mode analysis}

A total of 193 units of experience feedback were collected from all CGN nuclear power plants. All kinds of event data of main condensers were statistically analyzed, as shown in Figure 2.

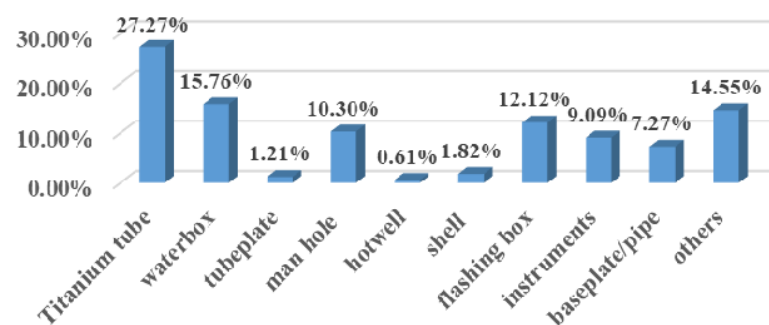

Figure 2. Failure parts of main condensers in CGN nuclear power plants

\subsubsection{Aging state management}

Preventive maintenance work plan of main condensers in Daya Bay nuclear power plants can be obtained by collection of maintenance programs and then analysis. Compared with general inspection and maintenance measures in the industry and the guiding management method given by the manufacturer, it can be seen that most of industry recommendation or manufacturer's guidance management methods have been carried out in the recommended period or the period adjusted according to the actual situation in Daya Bay nuclear power plant. The maintenance state is normal and there is no significant failure to be evaluated, so it is considered that the aging mechanism of main condensers in Daya Bay plants has been effectively managed by the current strategy and at the same time, the aging effect has been monitored in time in line with the management methods recommended by the industry or by the manufacturer.

In a word, industry experience feedback is reference to the Daya Bay main condensers operating under the current maintenance strategy. In the following paper, the aging life of main condensers is evaluated according to the plugging rate of Titanium tubes.
The recommended life of main condensers in nuclear power plants is blank at present in China. Under normal circumstances, main condenser design is such that there is typically excess surface area available in the form of extra tubes to allow to be plugged without reducing the effective heat transfer capacity of the unit ${ }^{[4]-[5]}$, which is called plugging margin.

As illustrated in Figure 3, the remaining life of main condenser is determined by the remaining life of the tube buddle, while the remaining life of tube buddle is relative to the plugging rate. With increase of the unit operating time, the plugging rate will increase, which reduces the heat transfer area and further reduces heat transfer capacity. Caused by the reducing of heat transfer capacity, the back pressure of the unit will rise, which will affect the unit output power and even affect the unit safety if the back pressure rises too much, because alarm value and trip value is set in the unit vacuum system. On the other hand, comparing the main condenser replacement cost and unit output power loss will cause an economic problem. In one word, the main condenser remaining life is a comprehensive life evaluating unit safety and economy.

The main condenser remaining life assessment model established in this paper is as illustrated in Figure 4, which fills the blank of main condenser remaining life assessment in domestic nuclear power plant.

First of all, Operating and maintenance condition assessment must be carried out, which includes the following records and data.

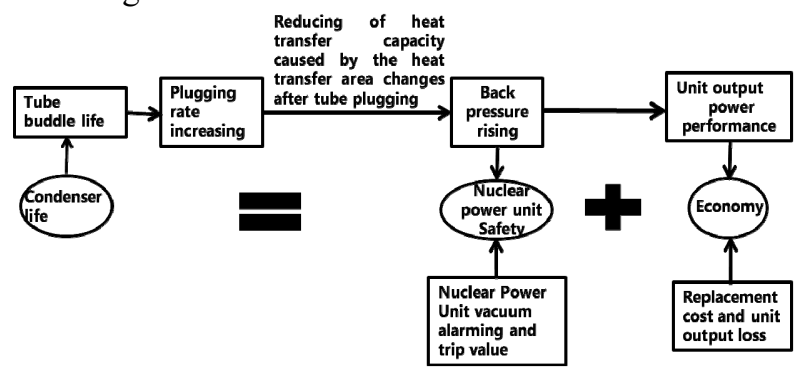

Figure 3. analysis of main condenser remaining life

\subsection{3 remaining life assessment}




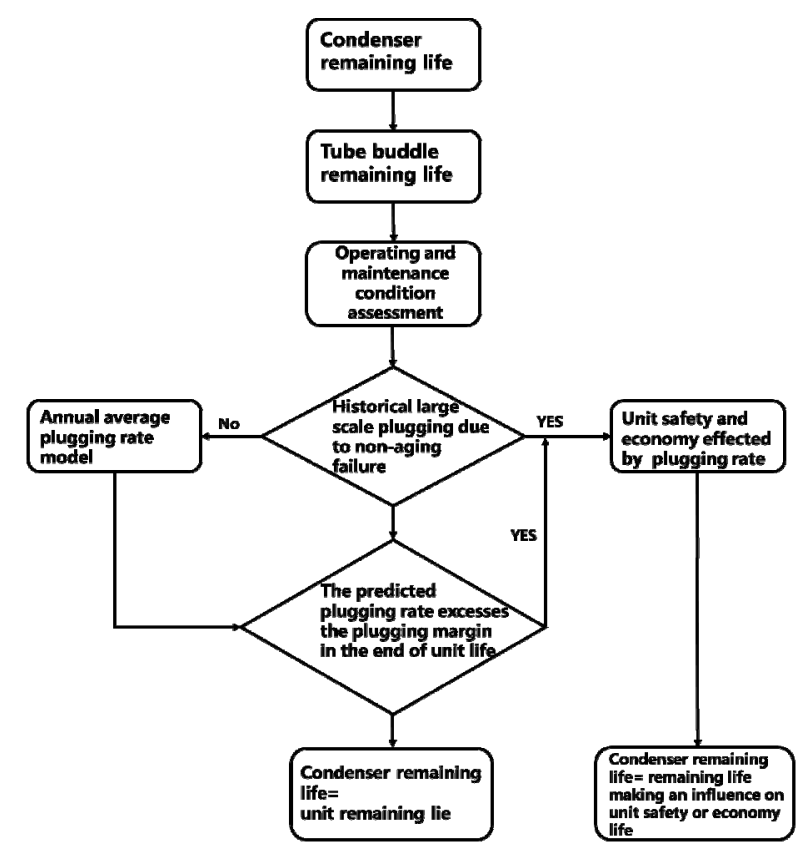

Figure 4. main condenser remaining life assessment model

Operation and Maintenance Records Appropriate tube plugging and other maintenance records reveal present and past problems within the main condenser. This includes the rate at which the conditions might be changing. In addition to providing location and date of plugging, possible reasons for failure should be recorded.

Historical Data - Industry data defining expected component life could provide a basis for more extensive condition analysis.

Non-Destructive Examination (NDE) - The use of NDE testing can provide valuable information on the remaining life of main condenser components. Testing techniques include: Visual Inspection (VI), Dye Penetrant Testing (PT), Magnetic Particle Testing (MT), Eddy Current Testing (ET), and Ultrasonic Testing (UT).

After operating and maintenance condition assessment, if there is a large scale of tube plugging due to historical failure, the comprehensive evaluation of the impact of tube plugging rate on the safety and economy of the unit will be carried out. At this time, the remaining life of the main condenser is remaining life making an influence on the unit safety of the unit or economic remaining life. if there is not a large scale of tube plugging due to historical failure, the annual average plugging rate model will be used to predict plugging rate at the end of the life of the power unit. If the predicted plugging rate does not exceed the designed plugging margin, the remaining life of the main condenser is the remaining life of the power plant. If the predicted plugging rate exceeds the designed plugging margin, the comprehensive evaluation of the impact of the plugging rate on the safety and economy of the unit needs to be carried out, and then the remaining life of the main condenser is the remaining life making an influence on the unit safety of the unit or economic remaining life.

By using the above-illustrated method, the remaining life of main condensers in Daya Bay nuclear power plant can meet the requirement of 60 years under a License Renewal Program.

\subsection{Life cycle management strategy}

Accordingly, as the remaining life of of main condensers in Daya Bay nuclear power plant can meet the requirement of 60 years, therefore the life cycle management strategy is to keep the existing maintenance strategy. However, special attention should be paid to the aging condition of seals between tubesheets and water boxes and whether they should be replaced or not.

\section{Conclusion}

The life cycle management system for main condensers in nuclear power plant is established in this paper. Considering the equipment's aging and degradation, condition assessment, failure risk assessment, feedback experience, design life and so on, the life of main condensers in Daya Bay nuclear power plant is evaluated, the remaining life of main condensers can meet the requirement of 60 years under a License Renewal Program. Therefore, the life cycle management strategy is to keep the existing maintenance strategy. However, special attention should be paid to the aging condition of seals between tubesheets and water boxes and whether they should be replaced or not.

\section{References}

1. $\mathrm{He} \quad \mathrm{Yu}$ and $\mathrm{Pu}$ Jilong et al 2007 Devices \& Systems of 900 MW Pressurized Water Reactor Power Plant, ed Huang Houkun and Zhang Hui (China: Beijing),pp.1.

2. Xie Mengren and Qin Qiang et al 2017 Long Term Asset Management System and its Application in Nuclear Power Plant (China: Nanning), pp.2.

3. Chen Jun Qi and Ju Cunyou et al Establishment and Application of Long Term Asset Management System in nuclear power plant, Material Management,2018, pp.89-92.

4. Xie Mengren and Wang Chunhui et al Study on Long Term Asset Management System application in Nuclear Power Plant, Daya Bay Nuclear Power,2019, pp.87-88.

5. Heat Exchange Institute. Standards for steam surface condensers. 9th ed. Ohio, 1995. 